
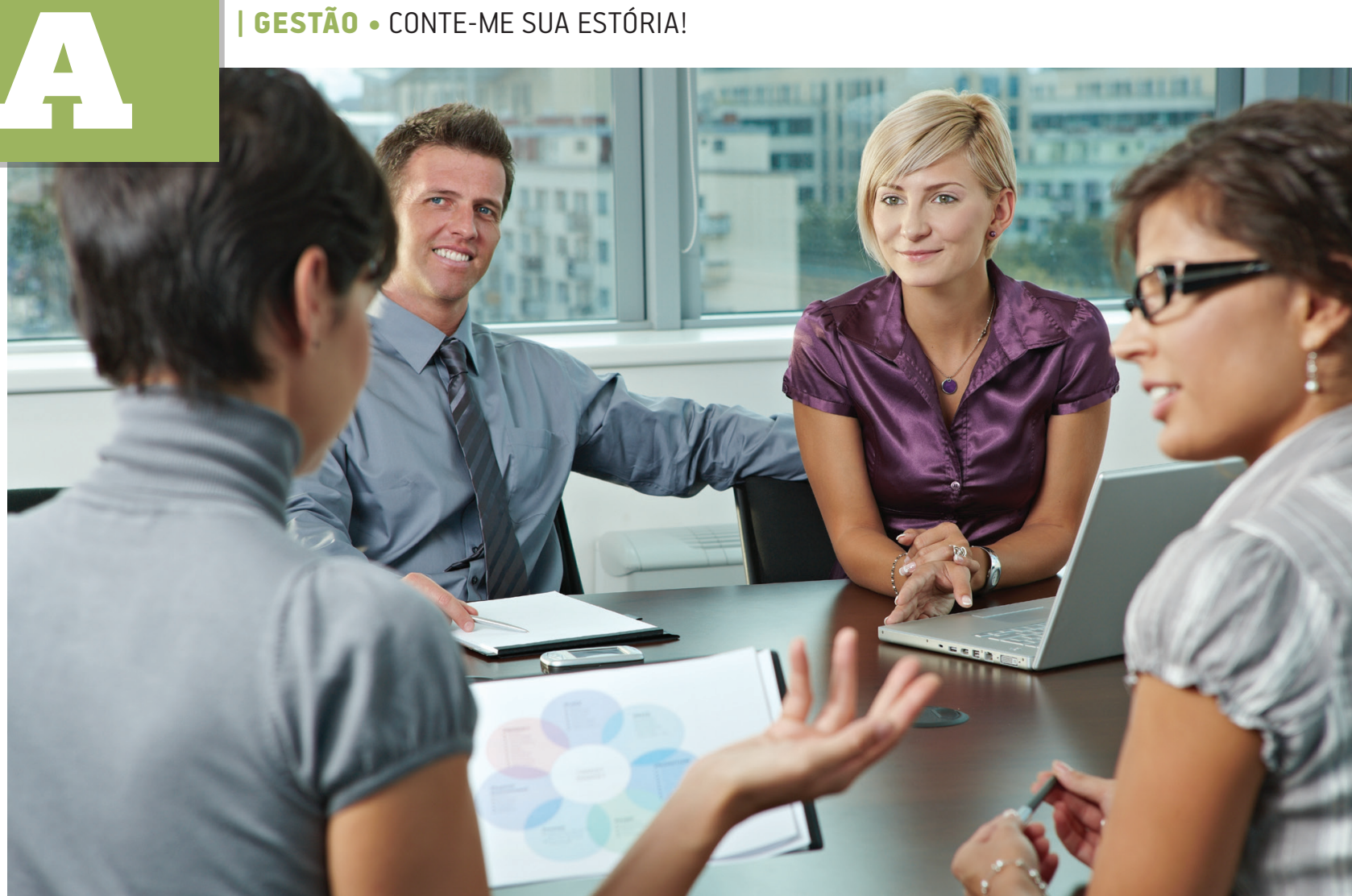

\title{
CONTE-ME SUA ESTÓRIA!
}

\section{ERA UMA VEZ... UMA TENDÊNCIA QUE CHEGOU PARA FICAR: 0 STORYTELLING. A UTILIZAÇÃO DE NARRATIVAS PARA CONTAR A TRAJETÓRIA E TRANSMITIR OS VALORES DAS INSTITUIÇÕES TEM TRAZIDO BONS RESULTADOS AO MUNDO EMPRESARIAL}

\section{POR FERNANDO NOGUEIRA}

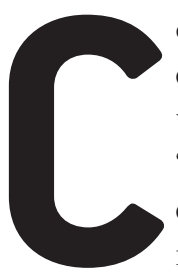

onhecida em inglês pela expressão storytelling (livremente traduzida como "contação de estórias"), essa ideia parte de uma premissa simples, mas poderosa: as estórias são uma das principais maneiras de comunicarmos fatos, valores, emoções e compartilharmos nossas experiências e aprendizados.

Não é de hoje que isso acontece: um bom "causo" sempre fez parte de conversas ao redor do café, dos discursos corporativos e até de algumas propagandas. A novidade é a importância que atualmente se dá às estórias e à ideia de que contá-las bem é uma habilidade que pode ser treinada e incentivada, em especial entre os gestores.

Mas afinal, o que é uma narrativa? Em sua essência, é o encadeamento cronológico de eventos e fatos a partir de um sentido comum e de uma relação de causa e efeito. Por exemplo, ao contar sobre o nascimento da empresa, o fundador está narrando - criando uma estória, selecionando alguns acontecimentos - como a instituição surgiu, qual a sua motivação, quais foram os passos importantes nessa trajetória.

\section{POR QUE CONTAR ESTÓRIAS?}

Estórias são importantes por que fazem muito mais do que apenas informar. Em primeiro lugar, elas transmitem valores e hábitos. Banners com listas de princípios da empresa pouco adiantam se não houver estórias reais que deem vida a palavras como sustentabilidade, 
criatividade, inovação e excelência. Uma única narrativa contada informalmente relatando como o diretor geral da corporação "não acredita nessa baboseira de voluntariado" pode colocar em risco todo o discurso da organização sobre responsabilidade social e ética.

Estórias podem ser poderosas ferramentas de inspiração e persuasão, não apenas quando queremos convencer alguém sobre um determinado assunto, mas também levá-lo à ação; não apenas fazê-lo conhecer e gostar do produto, mas comprá-lo; não apenas informá-lo sobre o programa de sugestões do RH, mas que ele de fato contribua com a medida.

Finalmente, elas também dão sentido à nossa experiência. Quando vivemos situações importantes, muitas vezes nos sentimos confusos. Ao contarmos como tudo ocorreu, geralmente damos significado ao acontecimento. Uma demissão pode gerar uma estória amarga em que nos sentimos vítimas de uma ação injusta da empresa ou do ex-chefe. Às vezes, porém, a vida e o tempo permitem que possamos enxergar o mesmo fato com outros olhos e um novo enredo. Quantas vezes não lemos entrevistas com empreendedores falando sobre como uma demissão se transformou em incentivo para ir atrás de seus sonhos? As narrativas que criamos e recriamos com os eventos que protagonizamos tem o potencial de mudar a nossa história.

\section{NARRATIVAS EMPRESARIAIS: ONDE E QUANDO USAR?}

Cada vez mais, empresas e gestores têm percebido o potencial das estórias e narrativas em suas práticas de comunicação. No ambiente corporativo, elas ajudam a humanizar a organização, derrubando o mito de que a comunicação empresarial é apenas técnica e racional. Pessoas não desligam seu lado emocional, intuição ou curiosidade apenas porque colocaram uma gravata ou um crachá.

Nas propagandas, é possível perceber o aumento expressivo na quantidade e qualidade de storytelling utilizado. Um caso famoso nos últimos anos é o da Domino's Pizza, que reconheceu em alguns comerciais veiculados no Youtube a baixa qualidade de suas pizzas e o esforço que estava fazendo para melhorar essa situação. Ao mostrar de forma clara os obstáculos e dificuldades pelos quais passava, a estória ficou mais poderosa e autêntica. Ao contatar os consumidores que tinham criticado

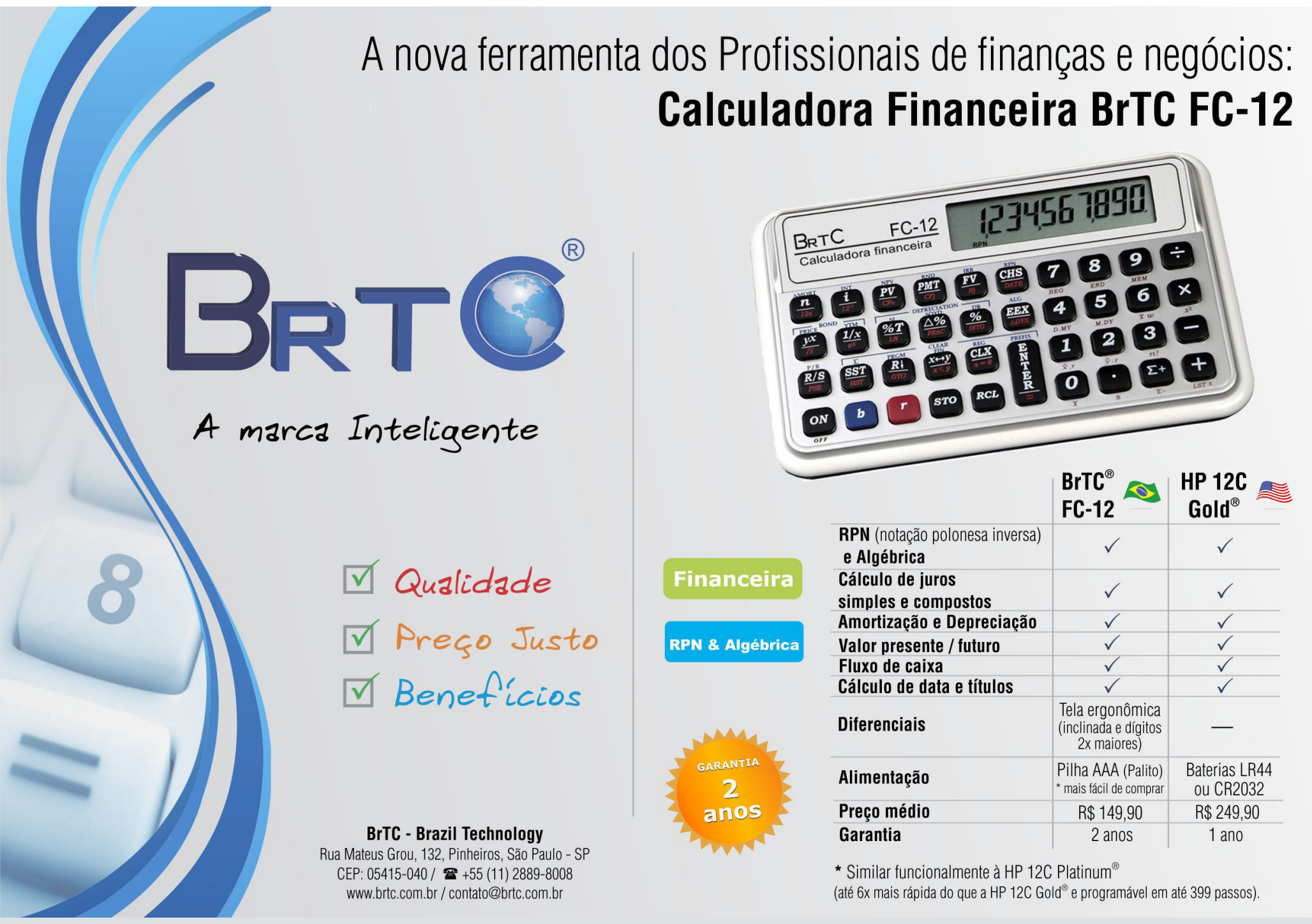


a pizza e pedir uma segunda chance, a Domino's conseguiu envolver um grupo mais amplo em sua narrativa, mostrando que o desejo de uma pizza melhor não era apenas da empresa, mas também do público. No Brasil, a rede Spoleto recentemente adotou uma abordagem semelhante, contando de forma bemhumorada como é o desafio de prestar um bom atendimento ao cliente.

Além de propagandas, as estórias começam a fazer parte do arsenal de quem tem contato direto com clientes. Indo além do PowerPoint com a apresentação da empresa, muitas organizações vêm treinando seus funcionários para que saibam contar boas estórias a respeito do produto ou serviço. Quando feito de forma competente, isso contribui para que o cliente entenda como aquele produto pode ajudá-lo a vencer suas dificuldades.

Finalmente, as estórias são também um ingrediente cada vez mais essencial na comunicação interna das organizações. Certa vez, o executivo de uma grande indústria brasileira contou como o seu esforço em atender a solicitação de uma única consumidora - que só voltaria a comprar produtos da empresa quando sua embalagem fosse reciclada - tornou-se uma poderosa estória para representar a política de sustentabilidade e ética. Foi uma forma simples e eficaz de comunicar aos funcionários da organização sobre a seriedade com que a diretoria encarava esse aspecto.

\section{VOLTANDO ÀS ORIGENS}

O que antes acontecia de forma natural e intuitiva - contar boas estórias - agora também pode ser treinado, desenvolvido e utilizado de forma estratégica. Não param de surgir livros, cursos e oficinas para ajudar quem se interessa pelo assunto, como pode demonstrar uma pesquisa no Google com termos como "business storytelling" e "storytelling para executivos".
Para os que têm receio de sair da cômoda apresentação.ppt, vale lembrar que a humanidade se comunica há milhares de anos com estórias, e só nas últimas décadas tornou-se dependente de slides, listas e bullet-points.

Uma sugestão final para o leitor testar o poder das narrativas em seu cotidiano. Na próxima entrevista que fizer com candidatos a uma vaga de

emprego, faça uma pergunta simples ao ver sua lista de habilidades e competências: "Você declara saber lidar com riscos e ser criativo. Você poderia me contar uma situação que viveu e demonstra isso?" A resposta deve dizer muito sobre o candidato e se ele deve fazer parte da sua história profissional.

FERNANDO NOGUEIRA > Professor da FGV-EAESP
fernando.nogueira@fgv.br

\section{CONTANDO BOAS ESTÓRIAS}

Em geral, bons contadores de estória sabem utilizar quatro elementos com muita clareza e habilidade: desejo, obstáculo, ação e autenticidade.

DESEJO: o que o protagonista da estória quer ou do que ele precisa? Quanto mais coisas estão em jogo, mais fácil será despertar o interesse de sua audiência. Sua empresa quer construir uma nova fábrica “apenas" para aumentar a lucratividade ou isso representa algo a mais? Quem sabe a chance de liderar um mercado importante pela primeira vez ou consolidar uma estratégia de inovação que começou 70 anos atrás com os fundadores? Quanto mais você deixar claro a importância dessa narrativa para você ou para sua organização, melhor será a estória.

OBSTÁCULOS: o que ou quem impede o protagonista de atingir seu objetivo? Nada mais chato e pouco efetivo em termos de comunicação do que um caso sem tensão ou conflito. Bons vilões fazem grandes super-heróis; bons adversários geram grandes rivalidades (pense: 0 que seria do Corinthians sem o Palmeiras, e vice-versa; ou do Google sem a Apple?). Quanto maior o obstáculo a ser enfrentado, mais valor tem a estória. Quando o Ronaldo Fenômeno comprou a primeira Ferrari foi um acontecimento! Um jovem de infância pobre que passou por todas as dificuldades do mundo finalmente tem a possibilidade de tornar real um sonho de criança. Se ele comprar o mesmo carro hoje em dia, o impacto dessa estória será muito menor, proporcional à ausência de dificuldade.

AÇÕES: o que pode ser feito para alcançar o objetivo em face dos obstáculos? Ações são quaisquer eventos que os personagens (protagonistas, rivais, parceiros) realizam ou sofrem no caminho para buscar o desejo. As boas estórias são compostas por ações significativas, ou seja, que alteram a situação para melhor ou pior. Em vez de contar detalhadamente as 15 reuniões necessárias para chegar à nova estratégia da empresa, por que não focar nas duas mais impactantes? Aquela no momento de desespero, em que tudo parecia perdido, e a outra em que o novo posicionamento da organização começou a ser desenhado, com todo o departamento trabalhando junto.

AUTENTICIDADE: é possivel acreditar nessa estória? O verdadeiro poder de um caso só aparece quando sua audiência sente que ele é real e você de fato acredita nele. A autenticidade funciona como uma vacina contra um dos principais riscos do mau uso das narrativas, que é o de manipulação emocional. Nesse ponto, também surge um dos principais desafios para os gestores responsáveis por liderar e compartilhar as estórias da corporação: o que fazer quando elas entram em conflito com seus valores pessoais? 